\title{
Interview: David King
}

\author{
Former chief science advisor to the UK government David King once said that last month's talks \\ in Copenhagen would be the "last chance saloon" for tackling climate change. But there is hope \\ beyond Copenhagen, says King. Olive Heffernan reports.
}

\begin{abstract}
What's your view on the Copenhagen Accord? Is it an important step forward or a failure?

The Accord is important because it establishes the $2{ }^{\circ} \mathrm{C}$ target as a global commitment, and before it was only a European Union commitment. It's also the first time we recognize globally that poor countries have to be supported in dealing with the impacts of climate change and in technology transfer, in a very real sense, by creating a flow of cash. And thirdly it includes the commitments to emissions reductions from all developed countries. But the accord doesn't go far enough.
\end{abstract}

In your book The Hot Topic, you said that Copenhagen was the "last chance saloon" for avoiding dangerous climate change. Is that still your view?

I don't think the protocol that I would like to see replace Kyoto could possibly have emerged at Copenhagen. The point when I understood that Copenhagen couldn't deliver on this was when the US cap-andtrade bill got watered down and took a long time going through Congress. And it has yet to be considered by the Senate. Everything, in my view, hinged around the ability of President Obama to deliver at Copenhagen. He couldn't because he is hostage to his Senate. So I wasn't expecting any other decision precisely because of [that] position.

But I'm still optimistic. We have a much clearer understanding now from the political community of the challenge of defossilizing the economy. In Kyoto, politicians felt that they could sign up to it, but perhaps didn't understand the scale of the challenge. Now they realize that they only have 40 years in which to do it.

What is the next important milestone for climate policy?

In my view, between now and November - when the next UN climate conference will take place in Mexico - the G20 needs to establish a clear timeline towards a global cap-and-trade scheme. I certainly believe that the UN conference is the place where a final deal needs to take place, but it almost has to be a rubber stamp. If we leave

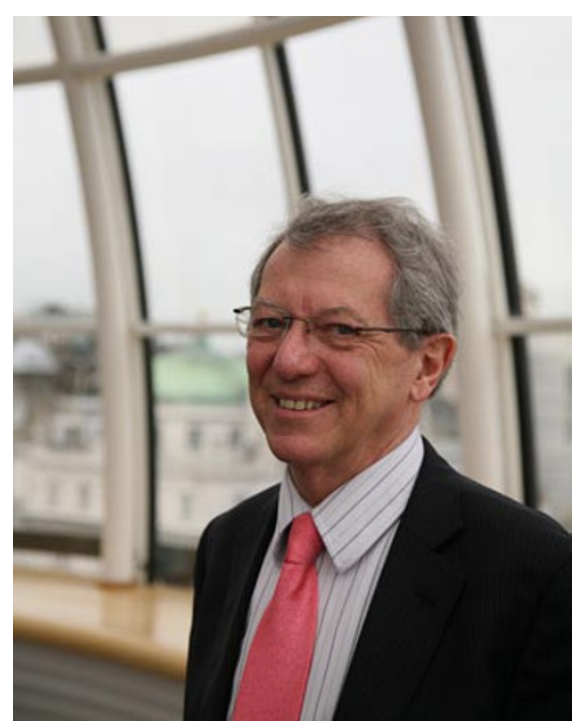

Former UK chief scientist Sir David King.

negotiators to meet twice a year we see very little progress, but as soon as we see heads of state step in, we see progress.

\section{The worst-case scenario is} that the rest of the world goes it alone without the US.

What should we be hoping for from the UN conference in Mexico?

I'm all for a simplification and a re-examination of the Kyoto Protocol. Global trade is the ultimate objective. We need a single scheme with a single price on carbon dioxide. Gordon Brown's idea of creating a flow of money of US $\$ 100$ billion a year by 2020 to poor nations is micromanaging a process that would be much better managed through a trading scheme. I think it's unrealistic to expect to have cap and trade [among] all developed nations by 2012, but I think this will be more feasible by 2020 .

In the meantime I'm fairly certain that we will have a set of parallel processes, with the US, the EU and [others] having their own cap-and-trade systems. I'm very keen to see the EU Emissions Trading Scheme invite some African countries into it, if their emissions are below two tonnes of carbon dioxide per person per annum and they can stay below two tonnes.

How important is US domestic legislation for an international treaty?

The US president is creating two approaches to managing the $\mathrm{CO}_{2}$ problem. The alternative to a cap-and-trade bill is for the president to turn to the Environmental Protection Agency (EPA) and regulate $\mathrm{CO}_{2}$ as a pollutant. Much more stringent measures would come through the EPA, and that's a threat being held over the Senate. For a bill to pass, it has to happen before the November election; after that Obama will face real challenges in getting it through. And there are attempts to block the EPA regulation. The worst-case scenario is that the rest of the world goes it alone without the US.

You gave evidence last week to the UK government on geoengineering. To what extent should we be investigating the potential of geoengineering?

I think the focus of research ought to be defossilizing the economy, but we may need to fall back on geoengineering. In terms of regulation, this would need to be addressed at a G20-level meeting, and it's of such importance that it should be raised to that level. For now, we need to move rapidly towards an international interim ban on the use of aerosols in the atmosphere for geoengineering. Once we've opened the door to field trials, we'll be slipping into larger-scale operations. This is something that needs to be put in the back drawer for 30 years.

doi:10.1038/climate.2010.05

Published online: 21 January 2010

Olive Heffernan is editor of Nature Reports Climate Change. David King is Director of the Smith School of Enterprise and the Environment, Oxford University, and scientific advisor to the investment bank UBS. 